\title{
Selvmordsatferd og yrke - er det noen sammenheng?
}

\author{
Ved Erlend Hem
}

\section{Noen yrker er forbundet med forhøyet selvmordsrate, men feltet er preget av mytedannelser og mangelfull dokumentasjon. I denne artikkelen vil jeg særlig omtale selvmordsatferd i menneskebehandlende profesjoner, som var emnet for min doktoravhandling.}

Jeg undersøkte selvmordsatferd i fem menneskebehandlende profesjoner i Norge: leger, tannleger, sykepleiere, teologer og politi (Hem, 2004). Bakgrunnen var at tidligere studier hadde vist høye selvmordsrater i de tre førstnevnte gruppene, det var påstander om det samme blant politifolk, mens én studie hadde vist lave rater blant prester.

Det er gjort få studier i Norge, men en analyse fra Statistisk sentralbyrå gir oversikt over dødeligheten i ulike yrkesgrupper for perioden 1970-80 (Borgan \& Kristofersen, 1986). Gruppen med den høyeste selvmordsd $\varnothing$ deligheten var leger, sykepleiere, tannleger og fysioterapeuter. Dessverre var disse yrkene slått sammen, slik at forskjeller mellom dem ikke fremgikk.

\section{Selvmord blant leger}

Leger er den yrkesgruppen som er grundigst studert med henblikk på yrke og selvmordsatferd. I løpet av de siste årene er det publisert to gjennomganger av litteraturen på feltet, og begge har kommet til samme resultat (Lindeman et al., 1996; Schernhammer \& Colditz, 2004). I en fersk metaanalyse som omfattet 25 studier for perioden 1960-2003, ble det vist en $\phi \mathrm{kt}$ selvmordsrate både blant mannlige og kvinnelige leger, men kvinnene var særlig utsatt (Schernhammer \& Colditz, 2004). Nyere studier viser imidlertid at forskjellen til andre grupper er i ferd med å bli mindre.

Vi $\varnothing$ nsket å unders $\varnothing$ ke selvmordsutviklingen i de fem menneskebehandlende

Tabell 1. Antall selvmord og selvmordsrater per 100000 personår, 1960-2000

\begin{tabular}{|c|c|c|c|c|c|}
\hline \multirow[t]{2}{*}{ Utdanning } & \multirow[t]{2}{*}{$\begin{array}{l}\text { Antall } \\
\text { selvmord }\end{array}$} & \multicolumn{3}{|c|}{ Menn } & Kvinner \\
\hline & & $\mathrm{N}$ & $\begin{array}{l}\text { Selvmordsrater ( } 95 \% \\
\text { konfidensintervall) }\end{array}$ & N & $\begin{array}{l}\text { Selvmordsrater ( } 95 \% \\
\text { konfidensintervall) }\end{array}$ \\
\hline Leger & 111 & 98 & $43,0(35,3-52,5)$ & 13 & $26,1(15,2-44,9)$ \\
\hline Tannleger & 34 & 32 & $32,9(23,3-46,5)$ & 2 & $5,8(1,5-23,2)$ \\
\hline Sykepleiere & 175 & 14 & $24,4(14,4-41,1)$ & 161 & $10,4(8,9-12,1)$ \\
\hline Teologer & 5 & 5 & $7,0(2,9-16,9)$ & - & - \\
\hline Politi & 28 & 28 & $19,5(13,4-28,2)$ & - & - \\
\hline $\begin{array}{l}\text { Andre } \\
\text { akademikere }\end{array}$ & 344 & 306 & $18,5(16,5-20,7)$ & 38 & $11,6(8,5-16,0)$ \\
\hline $\begin{array}{l}\text { Øvig } \\
\text { befolkning }\end{array}$ & 15008 & 10992 & $23,5(23,1-24,0)$ & 4016 & $8,0(7,8-8,3)$ \\
\hline Totalt & 15705 & 11475 & $23,4(23,0-23,9)$ & 4230 & $8,1(7,9-8,4)$ \\
\hline
\end{tabular}

profesjonene i perioden 1960-2000. Utdanningsregisteret og dødsårsaksregisteret ble koblet i Statistisk sentralbyrå (Hem et al., 2005a).

Tabell 1 viser antall selvmord og selvmordsratene i de fem gruppene sammenliknet med andre akademikere og den $\varnothing$ vrige befolkningen. Funnene bekreftet at selvmordsraten var forhøyet for leger sammenliknet med de andre gruppene. Selvmordsratene $\varnothing$ kte med alder blant legene (tabell 2). I den $\varnothing$ vrige befolkning var mønsteret annerledes, her var selvmord hyppigst $i$ aldersgruppen 40-60 år.

Et gledelig resultat var at selvmordsratene ble redusert i den siste tiårsperioden, slik at selvmordsraten i de menneskebehandlende profesjonene var signifikant lavere i 1990-årene enn i 1980-årene (tabell 3).

\section{Selvmord blant akademikere \\ Selvmordsratene for mannlige og} kvinnelige akademikere (ikke medregnet leger, tannleger og teologer) var henholdsvis 19 og 12 per 100000 , mens de tilsvarende tallene for den generelle befolkningen var 24 og 8 per 100000 (tabell 1). Raten blant mannlige akademikere var altså lavere enn i befolkningen for $\varnothing$ vrig, mens det var omvendt for kvinnelige akademikere. Det er imidlertid verdt å merke seg at kvinnelige akademikere ikke hadde forhøyet rate i siste tiårsperiode (tabell 3).

Tabell 2. Selvmordsrater med $95 \%$ konfidensintervall per 100000 personår, etter alder, 1960-2000

\begin{tabular}{|c|c|c|c|c|c|c|c|}
\hline Utdanning & Leger & Tannleger & Sykepleiere & Teologer & Politi & $\begin{array}{l}\text { Andre } \\
\text { akademikere }\end{array}$ & $\begin{array}{l}\text { Øvig } \\
\text { befolkning }\end{array}$ \\
\hline \multicolumn{8}{|l|}{ Menn } \\
\hline$<40 a ̊ r$ & $24,9(15,9-39,1)$ & $9,5(3,1-29,4)$ & $30,5(16,9-55,1)$ & - & $8,4(3,2-22,5)$ & $11,0(8,6-14,0)$ & $21,0(20,4-21,7)$ \\
\hline 40-59 år & $47,2(35,8-62,3)$ & $45,4(29,3-70,4)$ & $17,2(5,6-53,4)$ & $6,9(1,7-27,7)$ & $24,2(14,8-39,5)$ & $19,0(16,1-22,4)$ & $25,9(25,2-26,7)$ \\
\hline$\geq 60 a ̊ r$ & $63,7(44,2-91,6)$ & $41,8(21,8-80,3)$ & - & $12,3(4,0-38,3)$ & $26,4(13,2-52,8)$ & $30,7(25,2-37,8)$ & $23,8(23,0-24,8)$ \\
\hline \multicolumn{8}{|l|}{ Kvinner } \\
\hline$<40 \mathrm{ar}$ & $26,1(11,7-58,0)$ & - & $9,2(7,2-11,9)$ & - & - & $7,9(4,5-13,8)$ & $6,7(6,3-7,1)$ \\
\hline 40-59 år & $15,0(4,8-46,5)$ & - & $13,3(10,6-16,6)$ & - & - & $13,6(8,6-21,6)$ & $9,9(9,5-10,4)$ \\
\hline$\geq 60$ år & $58,6(22,0-156,0)$ & $27,2(6,8-108,8)$ & $7,4(5,0-11,1)$ & - & - & $19,3(9,7-38,6)$ & $7,4(7,0-7,9)$ \\
\hline
\end{tabular}


Tabell 3. Selvmordsrater med $95 \%$ konfidensintervall per 100000 personår, etter tiårsperiode, $1960-2000$

\begin{tabular}{|c|c|c|c|c|}
\hline Utdanning & $1960-1970$ & $1970-1980$ & 1980-1990 & $1990-2000$ \\
\hline \multicolumn{5}{|l|}{ Menn } \\
\hline Leger & $29,7(16,0-55,3)$ & $45,1(29,1-69,9)$ & $58,9(43,2-80,3)$ & $34,3(23,7-49,6)$ \\
\hline Tannleger & $17,8(5,7-55,1)$ & $60,8(36,0-102,6)$ & $14,0(5,3-37,4)$ & $38,1(21,1-68,8)$ \\
\hline Sykepleiere & - & $39,5(9,9-158,0)$ & $25,1(9,4-66,8)$ & $26,4(13,2-52,8)$ \\
\hline Teologer & $6,6(0,9-47,1)$ & - & $10,4(2,6-41,5)$ & $9,7(2,4-38,8)$ \\
\hline Politi & $21,9(9,8-48,7)$ & $12,7(4,8-34,0)$ & $23,7(13,1-42,8)$ & $18,1(8,6-37,9)$ \\
\hline $\begin{array}{l}\text { Andre } \\
\text { akademikere }\end{array}$ & $16,9(12,6-22,6)$ & $21,5(16,9-27,4)$ & $23,2(19,2-28,0)$ & $14,1(11,4-17,4)$ \\
\hline $\begin{array}{l}\varnothing \text { vrig } \\
\text { befolkning }\end{array}$ & $17,6(16,8-18,4)$ & $21,8(21,0-22,7)$ & $28,7(27,8-29,7)$ & $24,9(24,0-25,7)$ \\
\hline \multicolumn{5}{|l|}{ Kvinner } \\
\hline Leger & $45,9(11,5-183,4)$ & $41,8(13,5-129,6)$ & $29,7(11,1-79,1)$ & $16,1(6,1-42,9)$ \\
\hline Tannleger & $18,9(2,7-133,9)$ & - & - & $8,1(1,1-57,5)$ \\
\hline Sykepleiere & $7,3(4,5-11,9)$ & $11,7(8,5-16,1)$ & $12,1(9,1-16,0)$ & $9,7(7,5-12,5)$ \\
\hline Teologer & - & - & - & - \\
\hline Politi & - & - & - & - \\
\hline $\begin{array}{l}\text { Andre } \\
\text { akademikere }\end{array}$ & $6,3(1,6-25,0)$ & $15,9(7,2-35,5)$ & $19,6(12,0-32,0)$ & $8,0(4,7-13,5)$ \\
\hline $\begin{array}{l}\text { Øvig } \\
\text { befolkning }\end{array}$ & $5,3(4,9-5,7)$ & $7,4(7,0-7,9)$ & $10,4(9,8-10,9)$ & $8,6(8,1-9,1)$ \\
\hline
\end{tabular}

Selvmordsraten $\varnothing$ kte med alder for akademikerne (tabell 2). Vi kjenner ikke årsakene til dette. Kanskje er akademikeres identitet og selvrespekt tettere forbundet med yrket enn for mange andre grupper, og overgangen fra travelt yrkesliv til pensjonisttilværelse kan for noen være stor.

\section{Selvmordstanker blant leger}

Forekomsten av selvmordstanker og -fors $\varnothing \mathrm{k}$ blant leger ble studert i en landsomfattende tverrsnittsstudie $(\mathrm{N}=1064)$ (Hem et al., 2000). 26 leger (2,6 \%) rapporterte om alvorlige selvmordstanker siste år, mens tre leger $(0,3 \%)$ rapporterte om selvmordsfors $\varnothing \mathrm{k}$.

I en justert multivariat logistisk regresjonsmodell var en del forhold signifikant forbundet med alvorlige selvmordstanker. At kjønn (kvinner), sivilstand (enslig), angst og depresjon var risikofaktorer samsvarer med tidligere studier. Mer uventet var det at subjektive helseplager og å være anestesiolog var risikofaktorer.
"Personlige forhold" og "familiære forhold" var viktigste bidragende faktorer for utvikling av slike alvorlige selvmordstanker. "Sosiale forhold", "problemer i forbindelse med legeyrket" eller "andre forhold" var mindre viktige. Dette samsvarer med forventningene. Selv om flere forhold knyttet til arbeid og yrke kan spille inn ved selvmordsatferd, ligger som oftest hovedårsakene utenfor arbeidsplassen.

\section{Utvikling av selvmordsplaner blant unge leger}

Vi undersøkte også forekomsten av selvmordstanker og -fors $\varnothing \mathrm{k}$ hos medisinstudenter og unge leger i en landsomfattende longitudinell unders $\varnothing$ kelse. Alle medisinstudenter i Norge 1993-94 ble invitert til å delta $(\mathrm{N}=631)$ (Tyssen et al., 2004). Deltakerne fylte ut et spørreskjema i det siste året av medisinstudiet, samt i første og fjerde år etter embetseksamen.

Det viste seg at $6 \%$ av unge leger rapporterte å ha hatt alvorlige selvmordstanker i det foregående året. Et mindretall av disse (10 av 28) hadde søkt hjelp.
Prediktorer for alvorlige selvmordstanker var negative livshendelser, alvorlige depressive symptomer og personlighetstrekket sårbarhet.

Studien omfattet målinger over flere år. Dette gjorde at vi kunne unders $\varnothing$ ke kjennetegn ved dem som opplyste om selvmordstanker i medisinstudiet og seinere rapporterte om selvmordsplaner. En slik alvorlig utvikling er tidligere knapt studert, først og fremst på grunn av mangel på oppfølgingsstudier. 158 studenter rapporterte at de hadde hatt alvorlige selvmordstanker i løpet av livet. 13 av disse (8\%) utviklet selvmordsplaner. Bare fire av dem hadde $s \varnothing \mathrm{kt}$ hjelp. Uavhengige prediktorer for en slik overgang fra selvmordstanker til planer var personlighetstrekket realitetssvakhet og alvorlige depressive symptomer.

Samlet sett ser vi at depressive symptomer, visse personlighetstrekk og negative livshendelser er forbundet med alvorlige selvmordstanker og - planer. Dette er ikke overraskende, men det er en viktig dokumentasjon av risikofaktorer.

\section{Selvmord i politiet}

Politiet er på mange måter et myteomspunnet yrke, og det har vært en utbredt oppfatning at selvmordsraten er høy blant polititjenestemenn. Vi ønsket derfor å unders $\varnothing$ ke det empiriske grunnlaget for denne antakelsen. I en systematisk litteraturgjennomgang ble 20 studier inkludert (Hem et al., 2001). Resultatene sprikte $\mathrm{i}$ alle retninger, men det var ikke dokumentert at selvmordsraten i politiet var forh $\varnothing$ yet. Seinere har en metaanalyse bekreftet dette (Loo, 2003).

I perioden 1960-2000 ble det registrert 28 selvmord i politiet i Norge, alle hos menn (tabell 1). Dette tilsvarer en selvmordsrate på 19,5 per 100 000, som ikke er signifikant forskjellig fra den generelle befolkningen.

Både den internasjonale litteraturen og norske registerdata peker således i samme retning. Vi kan derfor konkludere med at myten om en høy selvmordsrate i politiet ikke kan bekreftes. Det betyr imidlertid ikke at selvmordsatferd ikke er et problem i politietaten. 


\section{Selvmordstanker i politiet}

Vi unders $\varnothing$ kte forekomsten av selvmordstanker og -fors $\varnothing \mathrm{k}$ i en landsomfattende tverrsnittsstudie også i politiet $(\mathrm{N}=3272$ ) (Berg et al., 2003). Alvorlige selvmordstanker og selvmordsfors $\varnothing \mathrm{k}$ siste år ble rapportert av henholdsvis 1,7 \% og $0,1 \%$. For $\varnothing$ vrig var resultatene i stor grad sammenfallende med studien blant legene.

Funnene tyder på at det er lav forekomst av selvrapporterte selvmordstanker og -fors $\varnothing \mathrm{k}$ både blant politi og leger sammenliknet med den generelle befolkning. Dette kan være uttrykk for at det i disse yrkesgruppene er lite "rop om hjelp", og at risikoen for $\mathrm{d} \varnothing \mathrm{d}$ er stor når de først bestemmer seg for å fors $\varnothing$ ke.

\section{Selvmord blant sykepleiere}

Blant sykepleiere var selvmordsraten forhøyet hos kvinner, men ikke hos menn (tabell 1). Dette er interessant, ettersom den forhøyede selvmordsraten blant kvinnelige leger delvis har vært forklart med vanskene i det å være underrepresentert $i$ et mannsdominert yrke. At mannlige sykepleiere har vært underrepresentert i et kvinnedominert yrke ser ikke ut til å virke på samme måte.

Blant sykepleierne fulgte selvmordsraten i ulike aldre det samme mønsteret som blant folk flest, det vil si at den høyeste raten var blant sykepleiere i aldersgruppen 40-60 år, mens den var lavere hos dem over 60 år (tabell 2).

\section{Selvmord blant tannleger}

Mannlige tannleger hadde høyere rater enn andre akademikere. Estimatene er usikre for kvinnelige tannleger pga. lavt antall registrerte selvmord $(\mathrm{N}=2)$ (tabell 1).

\section{Selvmord blant teologer}

Det var registrert fem selvmord blant mannlige teologer. Dette tilsvarer en lav rate både sammenliknet med andre akademikere og den generelle befolkning (tabell 1). Det kan indikere at personlig religiøs overbevisning virker beskyttende mot selvmordsimpulser, selv i perioder med stor personlig lidelse.

\section{Mulige forklaringer}

I litteraturen nevnes gjerne fire mulige forklaringer på forh øyede selvmordsrater i ulike yrker: psykiske lidelser, arbeidsstress, selvseleksjon av sårbare personer og tilgang til selvmordsmetoder (Boxer et al., 1995). Her har vi imidlertid lite empirisk kunnskap. Helsepersonell har både tilgang til og kunnskaper om selvmordsmidler, men dette er ingen tilstrekkelig forklaring, ettersom det samme også gjelder politi uten at selvmordsraten er forhøyet i den yrkesgruppen. Blant leger er det visse holdepunkter for overhyppighet av affektive lidelser, men dette er fremdeles omstridt. Det er imidlertid godt dokumentert at leger ofte har en inadekvat hjelps $\varnothing$ king (Rosvold, 2002, Hem et al., 2005b).

\section{Forebygging?}

Er det grunnlag for å tenke selvmordsforebygging i forhold til yrke? $\AA$ få til en mer hensiktsmessig hjelps $\varnothing$ king kan være viktig. Dette kan nok være en særlig utfordring i de menneskebehandlende profesjonene, der det ligger i yrkesut $\varnothing$ velsen at man skal yte, ikke motta, hjelp.

Selvmord finner sted i alle yrkesgrupper, og kan derfor også angå arbeidsplassen, men det er tvilsomt om det er grunn til å sette inn fokusert selvmordsforebyggende innsats her. Det mest relevante er antakelig å legge til rette for forhold som kan bidra til bedre generell fysisk og psykisk helse. Det er særlig viktig å være oppmerksom på ansatte som har psykiske (inklusive rusrelaterte) problemer, og hjelpe til slik at de kommer til behandling og eventuelt skjermes for arbeidsoppgaver som kan gjøre vondt verre. Det er trolig gunstig med bedriftslegeordninger eller andre systemer som gjør det mulig å fange opp dem som har somatiske og/eller psykiske problemer i en tidlig fase, slik at de kan få hjelp før problemene blir så store at det utvikles selvmordsfare.

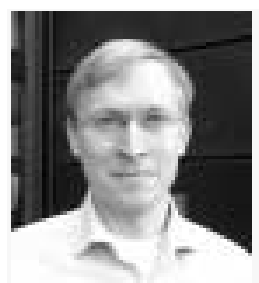

Erlend $\mathrm{H}$ em er postdoktorstipendiat dr.med. ved Avdeling for atferdsfag, Institutt for medisinske basalfag, Universitetet i Oslo.

\section{Referanser}

Berg, A.M., Hem, E., Lau, B., Loeb, M., \& Ekeberg, $\varnothing$. (2003). Suicidal ideation and attempts in N orwegian police. Suicide and Life-Threatening Behavior, 33, 302-312.

Borgan, J.-K., \& Kristofersen, L.B. (1986). D ødelighet i yrker og sosioøkonomiske grupper 1970-1980. Statistiske analyser nr. 56. Oslo: Statistisk sentralbyrå.

Boxer, P.A., Burnett, C., \& Swanson, N. (1995). Suicide and occupation: a review of the literature. Journal of Occupational and Environmental Medicine, 37, 442-452.

Hem, E. (2004). Suicidal behaviour in some human service occupations with special emphasis on physicians and police: a nationwide study. Doktoravhandling. Oslo: Universitetet i Oslo (www.legeforeningen.no/?id=46822 (24.4.2006)).

Hem, E., Berg, A.M., \& Ekeberg, Ø. (2001).

Suicide in police - a critical review. Suicide and Life-Threatening Behavior, 31, 224-233.

Hem, E., Grønvold, N.T., Aasland, O.G., \& Ekeberg, $\varnothing$. (2000). T he prevalence of suicidal attempts and suicidal ideation among $\mathrm{N}$ orwegian physicians. R esults from a cross-sectional survey of a nation-wide sample. European Psychiatry, 15, 183-189.

Hem, E., Haldorsen, T., Aasland, O.G., Tyssen, R., Vaglum, P., \& Ekeberg, Ø. (2005a). Suicide rates according to education with a particular focus on physicians in N orway 1960-2000. Psychological Medicine, 35, 873-880.

Hem, E., Stokke, G., Tyssen, R., Grønvold, N.T., Vaglum, P., \& Ekeberg, $\varnothing$. (2005b). Self-prescribing among young $\mathrm{N}$ orwegian doctors: a nineyear follow-up study of a nationwide sample. BMC Medicine, 3, 16 (www.biomedcentral.com/ 1741-7015/3/16 (24.4.2006)).

Lindeman, S., Läärä, E., Hakko, H., \& Lönnqvist, J. (1996). A systematic review on gender-specific suicide mortality in medical doctors. British Journal of Psychiatry, 168, 274-279.

Loo, R. (2003). A meta-analysis of police suicide rates: findings and issues. Suicide and LifeThreatening Behavior 33, 313-325.

Rosvold, E.O. (2002). Physicians in illness and health: an epidemiological study on health- and illness behaviour among 19th and 20th century N orwegian physicians. Doktoravhandling. Oslo: Universitetet i Oslo (www.legeforeningen.no/ asset/20570/1/20570_1.pdf (24.4.2006)).

Schernhammer, E.S., \& Colditz, G.A. (2004). Suicide rates among physicians: a quantitative and gender assessment (meta-analysis). American Journal of Psychiatry, 161, 2295-2302.

Tyssen, R., Hem, E., Vaglum, P., Grønvold, N.T., $\&$ Ekeberg, $\varnothing$. (2004). T he process of suicidal planning among medical doctors: predictors in a longitudinal N orwegian sample. Journal of

Affective Disorders, 80, 191-198. 